\title{
Mitral valve-in-valve hemodynamic performance: An in vitro study
}

\author{
Morgane Evin, PhD, ${ }^{\text {a,b }}$ Carine Guivier-Curien, $\mathrm{PhD},{ }^{\mathrm{a}}$ Regis Rieu, $\mathrm{PhD},{ }^{\mathrm{a}}$ Josep Rodés-Cabau, MD, PhD, ${ }^{\mathrm{c}}$ \\ and Philippe Pibarot, $\mathrm{PhD}^{\mathrm{c}}$
}

\section{ABSTRACT}

Objectives: The valve-in-valve ( VinV) procedure may be used in high-risk patients with failed mitral surgical bioprostheses. The objective of this in vitro study was to assess the hemodynamic function of different VinV configurations.

Methods: A double activation duplicator was used to test 11 valve configurations (surgical bioprostheses alone) and $15 \mathrm{VinV}$ configurations (Sapien [Edwards Lifesciences, Irvine, Calif] implanted within the surgical bioprosthesis) under 8 different hemodynamic conditions. The internal orifice diameter (IOD) of the surgical bioprosthesis was measured with a Smartscope (OGP Multi Sensor Measuring Instruments, Singapore).

Results: The VinV procedure was associated with significant deterioration in antegrade hemodynamic parameters compared with valve configuration (effective orifice area, $1.51 \pm 0.21 \mathrm{~cm}^{2}$ vs $1.65 \pm 0.37 \mathrm{~cm}^{2} ; P<.001$ and regurgitant fraction, $11.5 \% \pm 7.2 \%$ vs $4.8 \% \pm 3.8 \% ; P<.001)$. Among the 120 tested experimental VinV situations, moderate or greater mitral stenosis occurred in 52 situations and mild or greater regurgitation occurred in 28 situations. The IOD of the surgical bioprosthesis was the main independent determinant of effective orifice area and regurgitant fraction. An IOD $<22 \mathrm{~mm}$ was associated with higher risk of significant mitral stenosis, particularly when the oversizing was $>20 \%$, and IOD $>23 \mathrm{~mm}$ was associated with higher risk of paravalvular regurgitation when oversizing was $<8 \%$.

Conclusions: This in vitro study shows that VinV within mitral surgical bioprostheses provides satisfactory hemodynamic results in the majority of patients. However, significant mitral stenosis is more likely to occur when the IOD of the surgical bioprosthesis is $<22 \mathrm{~mm}$, and particularly when the percentage of oversizing is $>20 \%$. Significant paravalvular regurgitation is rare and occurs with larger IODs and lower percentage of oversizing $(8 \%)$. ( $\mathrm{J}$ Thorac Cardiovasc Surg 2016;151:1051-9)

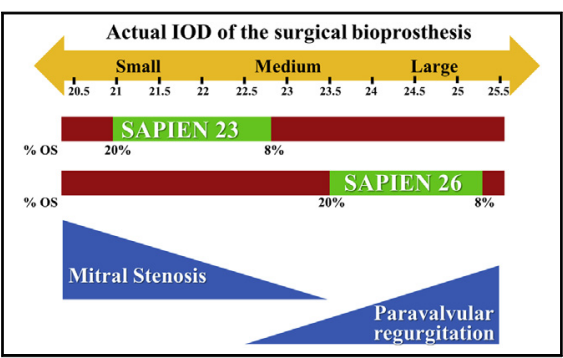

Decision aids schema for SAPIEN (Edwards Lifesciences, Ir vine, Calif) size choice for optimal valve-in-valve assembly hemodynamic results with IOD and percentage of oversizing thresholds for optimal choice of Sapien size for a failed mitral bioprosthesis. For Sapien 23, Sapien 20 could be considered for internal orifice diameter $<21 \mathrm{~mm}$ and oversized $>20 \%$ (red section on the left of the green bar for Sapien 23). Similarly, Sapien 29 could be considered for internal orifice diameter $>25.3$ and oversized $<8 \%$ (red section on the right of the green bar for Sapien 26).

\section{Central Message}

A small IOD $(<22 \mathrm{~mm})$ is associated with higher risk of mitral stenosis, particularly when the percentage of oversizing is $>20 \%$.

\section{Perspective}

The actual provided IOD and in vitro hemodynamic results of the different VinV assemblies may be useful to select the most appropriate size of Sapien transcatheter heart valve (Edwards Lifesciences, Irvine, Calif) for a given surgical bioprosthesis to optimize the hemodynamic performance of the VinV procedure Further studies are needed to extend these results to other models and sizes of all currently implanted prostheses.

See Editorial Commentary page 1060.

See Editorial page 906.
The valve-in-valve (VinV) procedure consists of implanting a transcatheter heart valve within another dysfunctional transcatheter or surgical bioprosthetic valve. ${ }^{1,2}$ The VinV procedure provides a valuable alternative for patients with

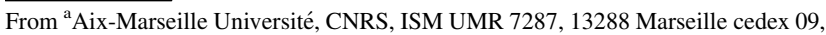
France; ${ }^{b}$ Protomedlabs, Marseille, France; and ${ }^{\mathrm{c}}$ Québec Heart and Lung Institute, Laval University, Québec, Canada.

M.E. was supported by a National Association for Research and Technology scholarship in cooperation with Protomedlabs. PP is the Canada Research Chair in Valvular Heart Disease funded by Canadian Institutes of Health Research (FDN143225; Ottawa, ON, Canada) and Heart and Stroke Foundation of Québec (Montreal, QC, Canada). a failed surgical bioprosthetic valve who are at high risk for repeated surgery. ${ }^{3-7}$ The only approved transcatheter valves allowing VinV procedure in the mitral position are the Sapien or Sapien XT balloon expandable valves

Received for publication March 10, 2015; revisions received Nov 11, 2015; accepted for publication Nov 20, 2015; available ahead of print Jan 5, 2016.

Address for reprints: Morgane Evin, PhD, GIBoc, Aix-Marseille University, UMR7278, CNRS/Aix-Marseille Univeristy, 163 av. de Luminy CP 910, 13288 Marseille Cedex 09, France (E-mail: evinmorgane@gmail.com). 0022-5223/ $\$ 36.00$

Copyright (C) 2016 by The American Association for Thoracic Surgery http://dx.doi.org/10.1016/j.jtcvs.2015.11.039 


$$
\begin{aligned}
& \text { Abbreviations and Acronyms } \\
& \begin{aligned}
\% \mathrm{OS} & =\text { percentage oversizing } \\
\text { AUC } & =\text { area under the curve } \\
\text { EOA } & =\text { Effective orifice area } \\
\text { IOA } & =\text { internal orifice area } \\
\text { IOD } & =\text { internal orifice diameter } \\
\mathrm{mTPG} & =\text { mean transvalvular pressure gradient } \\
\mathrm{RF} & =\text { regurgitant fraction } \\
\mathrm{VinV} & =\text { valve-in-valve }
\end{aligned}
\end{aligned}
$$

Scanning this QR code will take you to supplemental figures for this article.

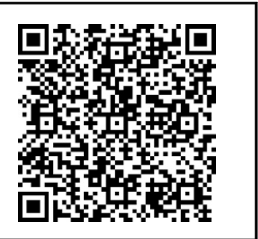

(Edwards Lifesciences, Irvine, Calif). ${ }^{8}$ The VinV procedure within failed surgical bioprostheses remains an off-label use of transcatheter valves and there is no precise recommendation about which model and size of transcatheter valve should be used for which model of surgical bioprosthesis.

There have been very few in vitro hemodynamic studies of VinV in normal or failed surgical bioprostheses ${ }^{9-11}$ and these studies were limited to either Sapien valves deployed within Carpentier-Edwards bioprostheses or home-made transcatheter valves deployed within various surgical bioprostheses.

The objectives of this in vitro study were to assess the hemodynamic performance of the VinV procedure using the Sapien valve within several different types and sizes of surgical mitral bioprostheses and under various hemodynamic conditions; and to determine which factors related to the transcatheter valve, the surgical bioprosthesis, or the hemodynamic conditions have a significant effect on the hemodynamic outcome of the VinV procedure.

\section{METHODS}

\section{Experiment Conditions}

A double activation pulsed duplicator, previously described by Tanné and colleagues, ${ }^{12}$ was used for this study (Figure E1). The fluid used was a water glycerol solution with temperature fixed at $37^{\circ} \mathrm{C}$ and viscosity fixed at $3.8 \pm 2 \mathrm{cP}$. Eight different hemodynamic conditions (Table 1) were tested for each valve (surgical bioprosthesis is tested alone) and VinV configuration (transcatheter deployed in surgical bioprosthesis) (Table E1) by varying the following parameters: mitral flow volumes $(70$ or $90 \mathrm{~mL})$, heart rate $(45$, 70 , and $120 \mathrm{bpm}$ ), mitral flow profiles (E/A wave velocity ratio of $0.5,1.0$, and 1.5), and mean aortic pressure (40, 100, and $160 \mathrm{~mm} \mathrm{Hg}$ ).

\section{Tested Valve and VinV Configurations}

Two main categories of valve and VinV configurations (Table E1) were tested in the mitral position of the pulse duplicator: Surgical bioprostheses alone (valve configuration) and VinV using a Sapien prosthesis deployed within different models and sizes of surgical bioprosthesis (VinV configuration).
Valve configuration. Surgical bioprostheses included 1 model of pericardial bioprostheses (Manufactured by Edwards Lifesciences) and 2 models of porcine bioprostheses (Manufactured by St Jude Medical, St Paul, Minn, and Medtronic Inc, Minneapolis, Minn). Several sizes were tested for each model (Figure E2 and Table E1), leading to 11 valve configurations. The 3 tested models had different designs: Edwards' model had a low straight sewing ring and small struts, the St Jude model had a bombed sewing ring with large strut, and the Medtronic model had a straight high sewing ring and large struts. The 11 surgical valves tested in this study had normal function and had never been implanted. Eighty-eight different valve experimental situations (ie, 11 valve configurations $\times 8$ hemodynamic conditions) were thus performed.

VinV configuration. Cheung and colleagues ${ }^{13}$ suggest selecting the Sapien valve size according to the surgical bioprosthesis internal orifice diameter (IOD) provided by the manufacturer and reduced by $10 \%$; that is, the Sapien 23 is implanted in bioprostheses having an IOD $<21.5 \mathrm{~mm}$ and the Sapien 26 is implanted in bioprostheses with an IOD between 21.5 and 24.5. In the present study, the actual IOD of the surgical bioprosthesis was measured with a Smartscope (OGP Multi Sensor Measuring Instruments, Singapore) (Table E1,C). The size of the Sapien prosthesis was chosen according to the actual IOD: the Sapien 23 was used when the IOD was $<22 \mathrm{~mm}$ and a Sapien 26 was used when the IOD was between 23 and $25 \mathrm{~mm}$. In cases of IOD between 22 and $23 \mathrm{~mm}$ both the Sapien 23 and the Sapien 26 were tested. We also did this additional experiment when there was report in the literature of use of both Sapien sizes for a given model and size of bioprostheses. In total, 15 different VinV configurations were tested (Table E1) and for 4 of them, we tested both Sapien sizes, resulting in 120 VinV experimental situations ( 15 VinV configurations $\times 8$ hemodynamic conditions). Percentage of oversizing $(\% \mathrm{OS})$ was calculated from the nominal orifice area of the Sapien valve when fully deployed $\left(4.15 \mathrm{~cm}^{2}\right.$ for Sapien 23 and $5.31 \mathrm{~cm}^{2}$ for Sapien 26$)$ and measured internal orifice area (IOA) of the surgical bioprosthesis: $\% O S=100 \times[$ SAPIEN nominal area-IOA]/IOA.

The implantation procedure of the assembly was performed outside of the simulator before introducing it into the pulsed duplicator (Figure E2, $E$ and $F$ ). Positioning of the SAPIEN valve within the surgical bioprosthesis was performed as recommended in Ferrari ${ }^{14}$ and Webb and colleagues $^{7}$; that is, the atrial border of the Sapien valve stent was positioned 1 to $2 \mathrm{~mm}$ above the sewing ring of the bioprostheses (Figure E2, F). Axial positioning was adjusted to align Sapien leaflet junctions with bioprosthesis leaflet junctions for each VinV configuration. Balloon inflation pressure was fixed at 8 bar.

\section{Measurement of Hemodynamic Parameters}

The diastolic and systolic flow volumes were measured by an electromagnetic flowmeter (Probe 95 [Carolina Medical, East Bend, $\mathrm{NC}$, internal diameter $30 \mathrm{~mm}$, accuracy $\pm 2 \mathrm{~mL} / \mathrm{min}$ ) located $5 \mathrm{~mm}$ upstream of the mitral valve. From the flowmeter measurements, the closing volume (backflow volume during the closure of the valve), leakage volume (backflow volume when the prosthesis is closed), and total regurgitant volume (sum of closing and leakage volumes) were calculated. The regurgitant fraction $(\mathrm{RF})$ was calculated as $\mathrm{RF}=100 \times$ (regurgitant volume/diastolic flow volume).

Pressures were measured in the left atrium, the left ventricle, the pulmonary circulation, and the aorta using 4 pressure catheters (Millar MPR 500 [Millar Sensor System Solution, Houston, Tex]; accuracy range, $\pm 0.5 \% ;-50$ to $300 \mathrm{~mm} \mathrm{Hg}$ ). Transprosthetic flow velocity was measured by continuous wave Doppler. Mean transvalvular pressure gradients (mTPGs) were deduced from Doppler measurements. The effective orifice area (EOA) was calculated with the use of the continuity equation method by dividing the diastolic flow volume measured by the flowmeter by the time velocity integral of the transprosthetic flow velocity envelope obtained by Doppler. 
TABLE 1. Hemodynamic conditions tested

\begin{tabular}{|c|c|c|c|c|c|c|c|c|}
\hline \multirow{2}{*}{$\begin{array}{l}\text { Valve-in-valve } \\
\text { configuration }\end{array}$} & \multicolumn{8}{|c|}{ Hemodynamic condition } \\
\hline & $\mathbf{C}_{1}$ & $\mathbf{C}_{2}$ & $\mathrm{C}_{3}$ & $\mathbf{C}_{4}$ & $\mathrm{C}_{5}$ & $\mathrm{C}_{6}$ & $\mathbf{C}_{7}$ & $\mathrm{C}_{8}$ \\
\hline $\begin{array}{l}\text { Mitral diastolic flow } \\
\text { volume }(\mathrm{mL})\end{array}$ & 70 & 90 & 70 & 70 & 70 & 70 & 70 & 70 \\
\hline Heart rate (bpm) & 70 & 70 & 70 & 70 & 45 & 120 & 70 & 70 \\
\hline E/A ratio & 1.5 & 1.5 & 0.5 & 1.0 & 1.5 & 1.5 & 1.5 & 1.5 \\
\hline $\begin{array}{l}\text { Mean aortic } \\
\text { pressure }(\mathrm{mm} \mathrm{Hg})\end{array}$ & 100 & 100 & 100 & 100 & 100 & 100 & 40 & 160 \\
\hline
\end{tabular}

\section{Statistical Analysis}

Data were expressed as mean value \pm standard deviation and compared using $t$ tests, when appropriate. The relationship between the valve and the Vin V configurations were assessed using simple linear regression analyses. A general linear model was used to identify the independent determinants of the hemodynamic performance of the VinV procedure. Detailed description of the analysis can be found in the Appendix E1. Mitral flow volume, heart rate, and mean aortic pressure variables were entered as categorical variables. All statistical analyses were performed using the open source R software (R Foundation for Statistical Computing, Vienna, Austria). Receiver operating characteristic analyses were performed to determine the best cutoff values of the prosthesis-related factors to predict moderate or greater mitral stenosis $\left(\mathrm{EOA}<1.5 \mathrm{~cm}^{2} \text { and } \mathrm{mTPG}>5 \mathrm{~mm} \mathrm{Hg}\right)^{15,16}$ and mild or greater mitral regurgitation $(\mathrm{RF}>15 \%)^{15}$ in VinV configurations.

\section{RESULTS}

\section{Effect of VinV on Valve Hemodynamic Performance}

Figures 1 and 2 show the hemodynamic results in terms of EOA, mTPG, and RF for the 11 surgical valve configurations (88 experimental situations), and the 15 VinV configurations (120 experimental situations).

The VinV procedure with the Sapien valve was associated with significant deterioration in antegrade hemodynamic parameters (that is, decrease in EOA and/or increase in $\mathrm{mTPG}$ ) compared with the corresponding valve configuration (surgical bioprosthesis alone) in most of the tested configurations (Figures 1 and 2): Epic (St. Jude Medical, St. Paul, Minn) 27 with Sapien 26; Epic 29, Epic 31, and Epic 33 with Sapien 23 or 26; Mosaic (Medtronic, Minneapolis, Minn) 27 with Sapien 26 and Mosaic 29 with Sapien 23 or 26; and Magna (Edwards, Irvine, Calif) 27 with SAPIEN 26.

VinV was associated with significant improvement in hemodynamic parameters (EOA and $\mathrm{mTPG}$ ) in the 3 following configurations: Epic 25 with Sapien 23, Epic 27 with Sapien 23, Mosaic 25 with Sapien 23, and Magna 25 with Sapien 26.

There was no significant change in antegrade hemodynamic parameters with VinV in the Mosaic 31 with Sapien 26. Overall, the average EOA was $1.65 \pm 0.37 \mathrm{~cm}^{2}$ in valve configurations versus $1.51 \pm 0.21 \mathrm{~cm}^{2}$ in VinV configurations, respectively $(P<.001)$; the average RF was $4.8 \% \pm 3.8 \%$ versus $11.5 \% \pm 7.2 \%$, respectively $(P<.001)$. The EOA was $<1.5 \mathrm{~cm}^{2}$, indicating the presence of moderate mitral stenosis in 25 of the 88 valve situations and 49 of the 120 VinV situations. Only 3 of $120 \mathrm{VinV}$ situations were associated with severe mitral stenosis $\left(\mathrm{EOA}<1.0 \mathrm{~cm}^{2}\right)$.

The RF was unchanged with the VinV procedure compared with the corresponding valve configuration in the following tests: Epic 27 with Sapien 26 and Epic 31 with Sapien 26 and Magna 27 with Sapien 26, and it was significantly increased in all other configurations (Figure 2).

In the majority of the VinV configurations, the RF was $<15 \%$, which is considered as trivial regurgitation and not clinically significant. In several configurations (Epic 25 with Sapien 23, Epic 27 with Sapien 26, Epic 29 with Sapien 26, Epic 33 with Sapien 26, Mosaic 25 with Sapien 23, and Magna 25 and 27 with Sapien 26), the RF was $>15 \%$ but $<30 \%$, which is considered mild mitral regurgitation according to the guidelines ${ }^{15}$ (Figure 3). In 3 cases (Mosaic 29 with Sapien 23, Epic 29 with Sapien 23, and Mosaic 31 with Sapien 26), the RF was $>30 \%$ and so consistent with moderate regurgitation. Overall, mild or greater mitral regurgitation was present in 2 of the 88 valve configurations and 28 of the $120 \mathrm{VinV}$ configurations $(P<.001)$ (Figure 3$)$. There was no case of severe regurgitation (RF $\geq 50 \%$ ).

\section{Comparison of Sapien 23 Versus Sapien 26 Within the Same Surgical Bioprosthesis}

In 4 surgical bioprostheses with intermediary IODs, we were able to implant and compare the Sapien 23 versus the Sapien 26 within the same bioprosthesis (Figure 4). In the Epic 27 which has a somewhat smaller IOD, the VinV with the Sapien $23(\% \mathrm{OS}, 10.4 \%)$ resulted in better EOA and mTPG than the Sapien 26 (\%OS, 41.1\%) and similar RFs. In the Epic 29, the Sapien $23(\% \mathrm{OS},-1.5 \%)$ was associated with higher RF compared with the Sapien 29 (\%OS, 25.9\%). As a consequence EOA remained similar mTPG increased. For the 2 Mosaic bioprostheses, the hemodynamic results were similar with Sapien 23 versus Sapien 26 (Figure 4).

\section{Factors Influencing Hemodynamic Results of VinV}

Table 2 presents univariate and multivariable regression analyses of the prostheses- (surgical and transcatheter) related factors and the hemodynamic factors influencing the EOA, mTPG, and RF of the mitral VinV configurations. The mean aortic pressure $(P=.02)$ and the actual IOD of the surgical prosthesis $(P<.001)$ were the factors independently related to the EOA. Mitral flow volume $(P=.007)$, and IOD of the surgical bioprosthesis $(P<.001)$ were independently associated with mTPG. Heart rate $(P<.0001)$ and mean aortic pressure $(P<.001)$ were independently associated with RF. Bioprosthesis model was not associated with hemodynamic parameters both in univariate and multivariable analyses. Overall, these results show that the IOD of the surgical bioprosthesis is the main prosthesis-related factor influencing the hemodynamic results of the VinV. The 


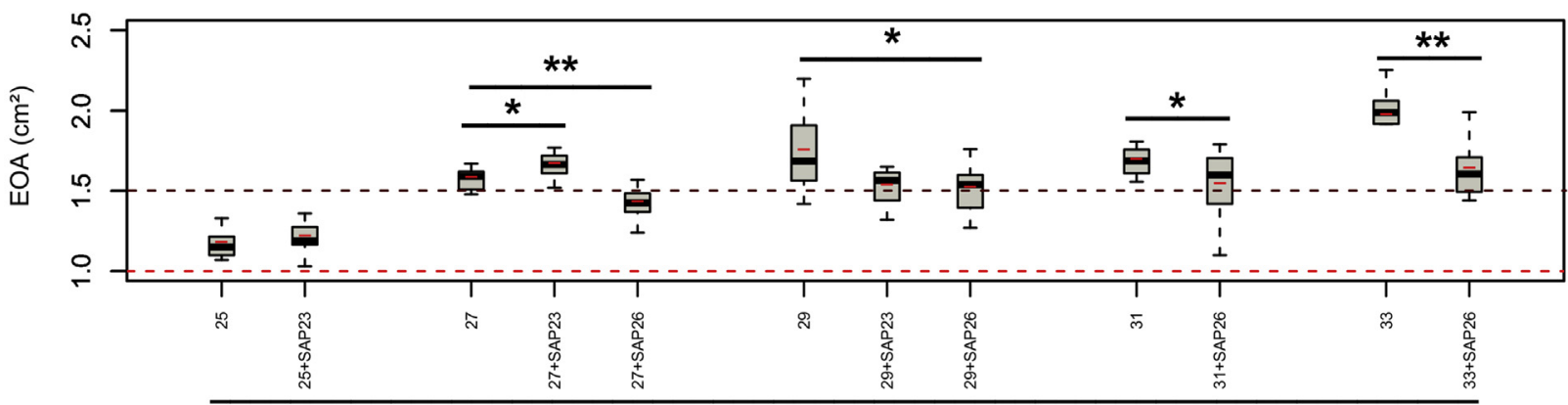

Epic
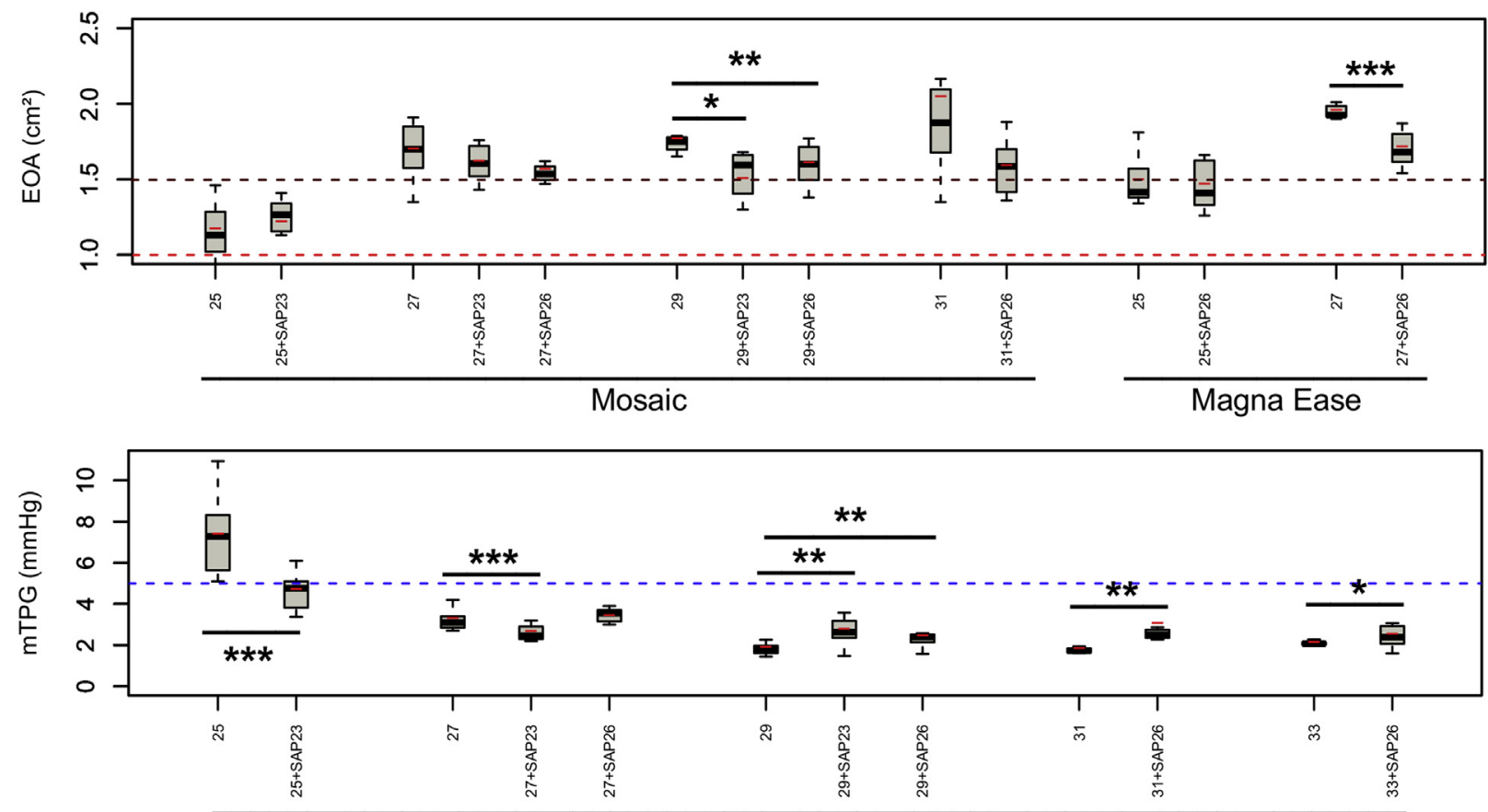

Epic

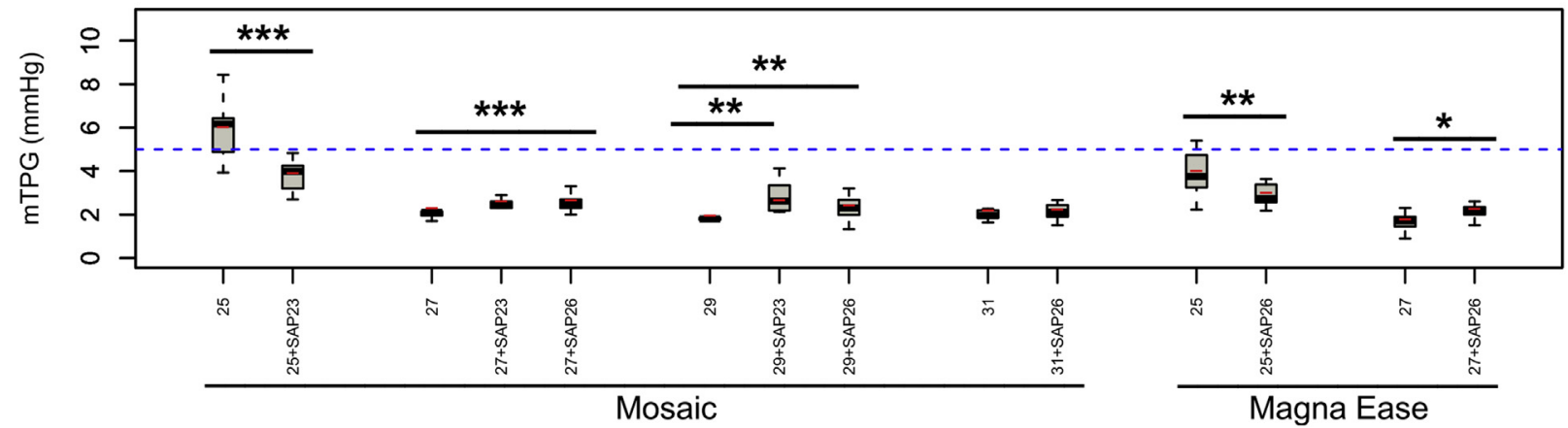

FIGURE 1. Effective orifice areas (EOAs) and mean transvalvular pressure gradient $(m T P G)$ for the different valve and valve-in-valve configurations. Hemodynamic results of valve (left) and valve-in-valve configurations (right) are presented. The boundaries of the boxes represent the first and third quartiles, the black bar within the boxes represent the median value, the red bar within the box represents the mean value, and the black dashed lines and bars represent the minimum and maximum values. The red dashed line indicates an EOA of $1.0 \mathrm{~cm}^{2}$, which is the criteria for severe mitral stenosis in native valves ${ }^{16}$ and significant stenosis in mitral bioprosthetic valves. ${ }^{15}$ The black dashed line indicates an EOA of $1.5 \mathrm{~cm}^{2}$, which is considered as suggestive of moderate mitral stenosis. ${ }^{16}$ The blue dashed line indicates a mean mTPG of $5 \mathrm{~mm} \mathrm{Hg}$, which is the criteria for moderate mitral stenosis in native valves ${ }^{16}$ and significant stenosis in mitral bioprosthetic valves. ${ }^{15}$ SAP23, Sapien size 23 (Edwards Lifesciences, Irvine, Calif); SAP26, Sapien size 26 (Edwards Lifesciences). $* P<.05$ between groups. $* * P<.01$ between groups $* * * P<.001$ between groups. 

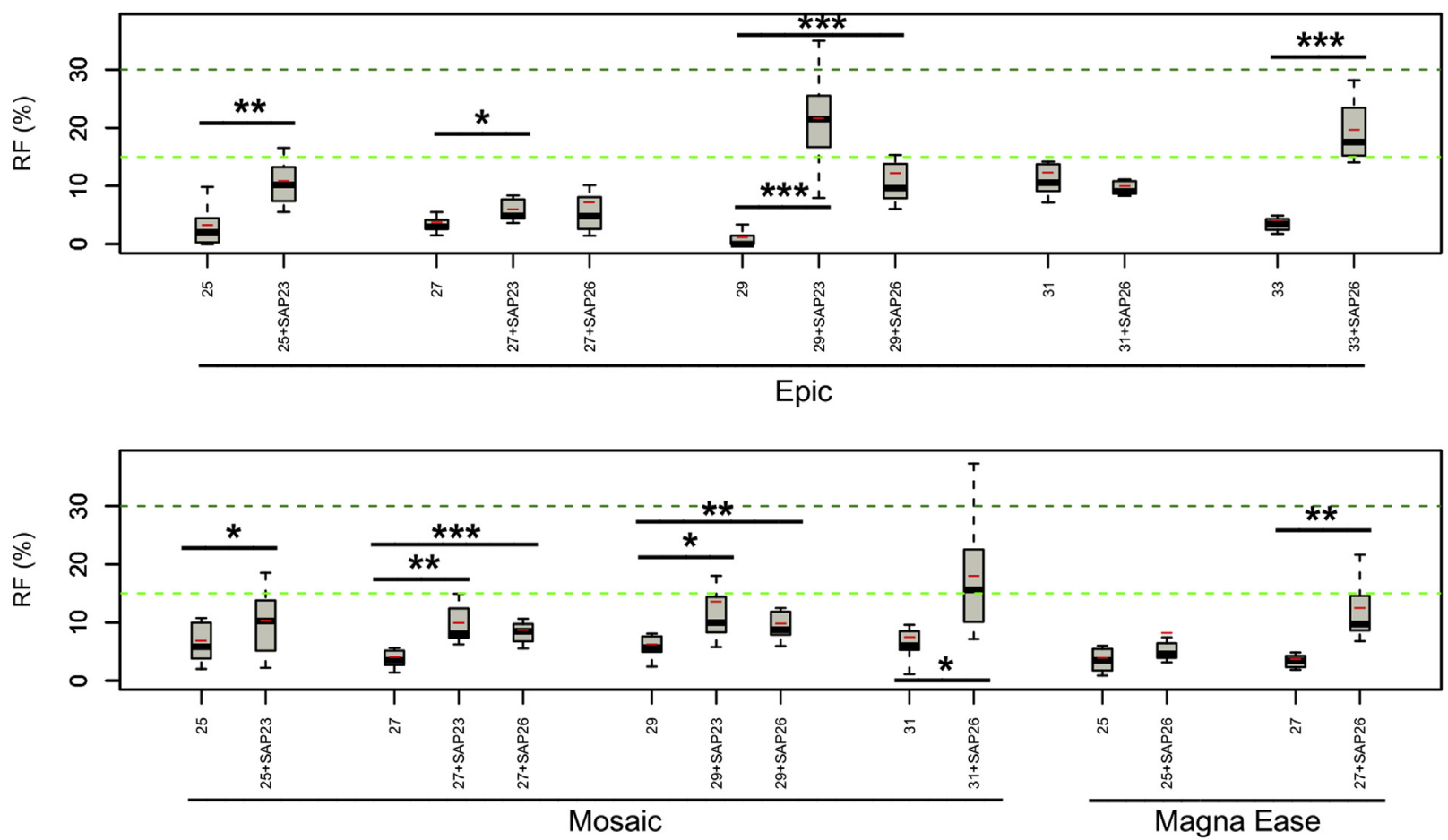

FIGURE 2. Regurgitant fraction $(R F)$ for the different valve and valve-in-valve configurations. The dark green and light green dashed lines indicate RFs of $30 \%$ and $15 \%$, which are the threshold for severe and moderate regurgitation, respectively. The boundaries of the boxes represent the first and third quartiles, the black bar within the boxes represent the median value, the red bar within the box represents the mean value, and the black dashed lines and bars represent the minimum and maximum values. ${ }^{15}$ SAP23, Sapien size 23 (Edwards Lifesciences, Irvine, Calif); SAP26, Sapien size 26 (Edwards Lifesciences).

ROC analysis (Figure E3 and Table E2) revealed that the cutoff value of IOD best predicting the risk of moderate or greater mitral stenosis $\left(\mathrm{EOA}<1.5 \mathrm{~cm}^{2}\right.$ ) is $<22.2 \mathrm{~mm}$ for VinV overall (area under the curve [AUC], 69.9\%), $<21.0 \mathrm{~mm}$ for the VinV with Sapien 23 (AUC, 84.2\%), and $<23.5 \mathrm{~mm}$ for VinV with Sapien 26 (AUC, 62.3\%). Thresholds for prediction of $\mathrm{mTPG}>5 \mathrm{~mm} \mathrm{Hg}$ were lower than those for EOA $<1.5 \mathrm{~cm}^{2}: 19.5$ for VinV Sapien 23. Regarding moderate mitral regurgitation, IOD thresholds for prediction of RF $>30 \%$ were $22.8 \mathrm{~mm}$ for Sapien 23 and 25.3 for Sapien 26, resulting in an overall threshold of $22.8 \mathrm{~mm}$.

Hence, when appropriate size of Sapien is used for a given IOD of surgical bioprosthesis $\geq 22 \mathrm{~mm}$, the results are generally satisfactory in terms of EOA and gradient. However, when the IOD is $\leq 22 \mathrm{~mm}$, there is a higher risk of significant mitral stenosis (Figure E3 and Table E2), particularly when the $\% \mathrm{OS}$ is $\geq 22 \%$ (Figure 3 ). The amount of valve regurgitation was generally higher for larger IOD ( $>22.8$ for Sapien 23 and $>25.3$ for Sapien 26) (Table E2) and in situations where the $\% \mathrm{OS}$ was $<8 \%$ (Figure 3 ).

\section{DISCUSSION}

The main findings of this study are that $\mathrm{VinV}$ within mitral surgical bioprostheses using the balloonexpandable Sapien valve provides good hemodynamic results in the majority of the models and sizes of tested surgical bioprostheses; however, VinV may cause significant mitral stenosis when the IOD of the surgical bioprosthesis is $<22 \mathrm{~mm}$. Furthermore, VinV may cause significant mitral regurgitation in surgical bioprostheses with the larger range of IOD for each Sapien size (Figure 5).

In most of the situations tested in this study, VinV was associated with significant decrease in EOA and/or increase in mTPG compared with the surgical bioprosthesis alone. The implantation of the Sapien valve may indeed reduce the IOD of the surgical bioprosthesis and thus its EOA. Nevertheless, the hemodynamics of the VinV assembly were adequate (ie, EOA $>1.5 \mathrm{~cm}^{2}$, mTPG $<5 \mathrm{~mm} \mathrm{Hg}$, and $\mathrm{RF}<15 \%$ ) in 54 of the 120 configurations. VinV procedure is currently reserved for patients with severely dysfunctional bioprostheses who at high or extreme risk surgical risk. VinV procedure is thus likely to significantly improve valve hemodynamic parameters in the vast majority of these patients.

Additionally, 36 of $88 \mathrm{VinV}$ configurations met the criteria for moderate mitral stenosis (EOA $<1.5 \mathrm{~cm}^{2}$ and $>1.0 \mathrm{~cm}^{2}$ ) and 4 met the criteria for severe stenosis $\left(\right.$ EOA $\left.<1.0 \mathrm{~cm}^{2}\right)$. Moreover, 20 of the $88 \mathrm{VinV}$ configurations had mild mitral regurgitation ( $\mathrm{RF}>15 \%$ and $>30 \%$ ) and 2 configurations had moderate or greater regurgitation (RF $>30 \%$ ). Moderate/severe mitral stenosis occurred 


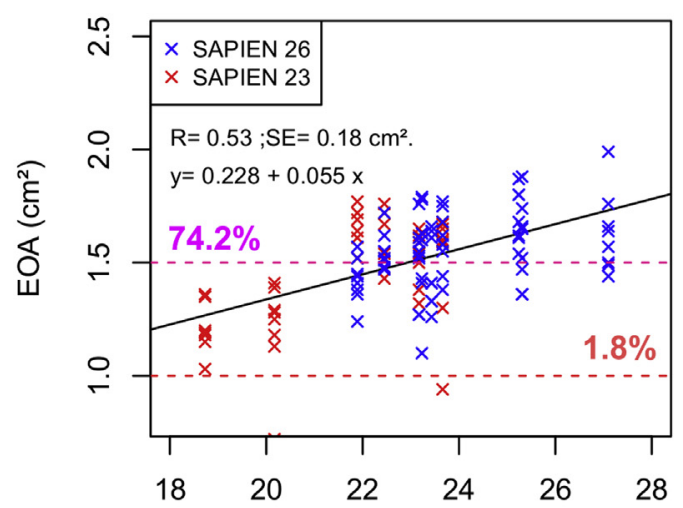

A

Internal diameter $(\mathrm{mm})$

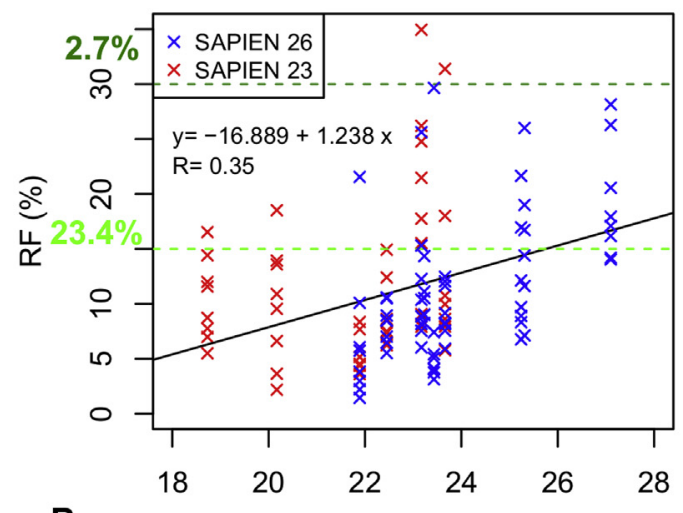

B

Internal diameter $(\mathrm{mm})$

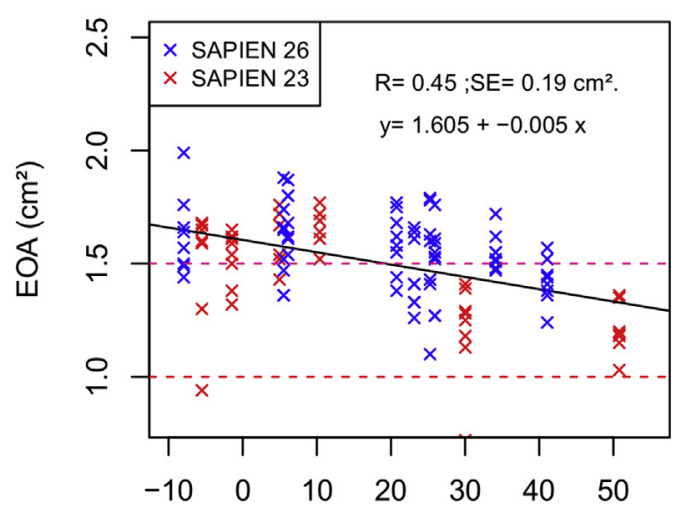

C

OS $(\%)$

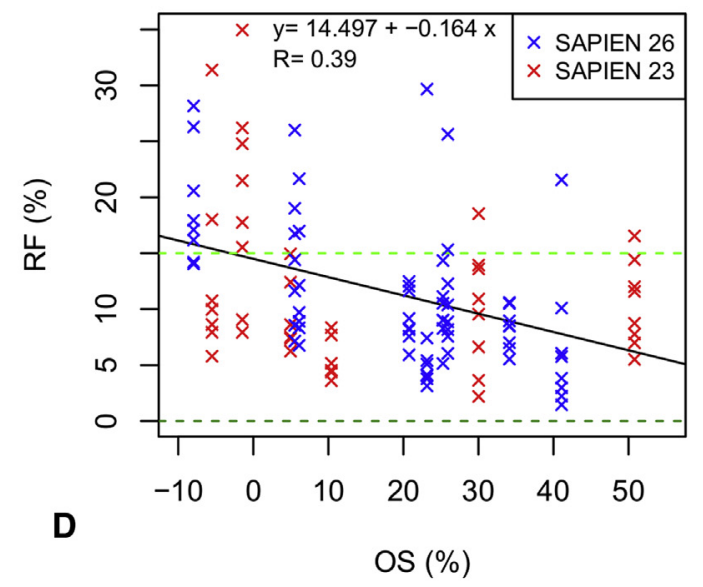

FIGURE 3. Relationship between the hemodynamic parameters of the valve-in-valve configuration and the surgical bioprosthesis internal orifice diameter (IOD) and percentage of oversizing ( $\% O S$ ). Correlation between the IOD of the surgical bioprosthesis (see Table 1) and the (A) effective orifice area (EOA) and $(\mathrm{B})$ regurgitant fraction $(R F)$ with regression line (black line) and regression equation. Correlation between the valve-in-valve configuration \% OS and the (C) EOA and (D) RF with regression line (black line) and regression equation. SAP23, Sapien size 23 (Edwards Lifesciences, Irvine, Calif); SAP26, Sapien size 26 (Edwards Lifesciences); SE, standard error.

more frequently when the IOD of the surgical bioprosthesis was small $(<22 \mathrm{~mm})$ and particularly when the $\% \mathrm{OS}$ was high $(\geq 22 \%$ ) (Figure 3). Mitral stenosis and regurgitation were more recurrent with high heart rate and mean aortic pressure configurations. The IOD of the surgical bioprosthesis is the main factor limiting the size of the Sapien valve for the VinV as well as its deployment as underlined for aortic position in Dvir and colleagues. ${ }^{17}$ Modest oversizing of the transcatheter valve is recommended to ensure adequate sealing between the transcatheter and surgical valves and therefore avoiding paravalvular regurgitation. To this effect, most of the cases of mild or moderate regurgitation occurred in VinV configurations where the $\%$ OS was $<8 \%$. On the other hand, important oversizing ( $\geq 22 \%)$ was associated with significant mitral stenosis, particularly in surgical bioprostheses with small IODs. Indeed, when a too-large Sapien valve is implanted within a small IOD, the valve stent is underdeployed, reducing further the IOD and the leaflets do not operate optimally. Hence, the optimal \%OS for mitral VinV appears to be between $8 \%$ and $20 \%$. In a few situations, we observed a significant improvement in the EOA and mTPG with the VinV procedure, compared with the bioprosthesis alone. This phenomenon occurred predominantly in the 25-mm surgical bioprostheses (Mosaic, Epic, and Magna) and might be related to slight expansion of the bioprosthesis stent by the radial force exerted by the deployment of the Sapien valve. The stents of the tested bioprostheses are semiflexible and it may be possible that the implantation of a balloon-expandable valve within such stents causes a slight expansion and thus an enlargement of the IOD. However, further studies are needed to confirm the occurrence of this phenomenon in vivo.

Our findings are consistent with the recommendation of Cheung and colleagues ${ }^{13}$ to systematically oversize the IOD provided by the manufacturer by $10 \%$ to select the size of the Sapien valve for the VinV procedure. However, 

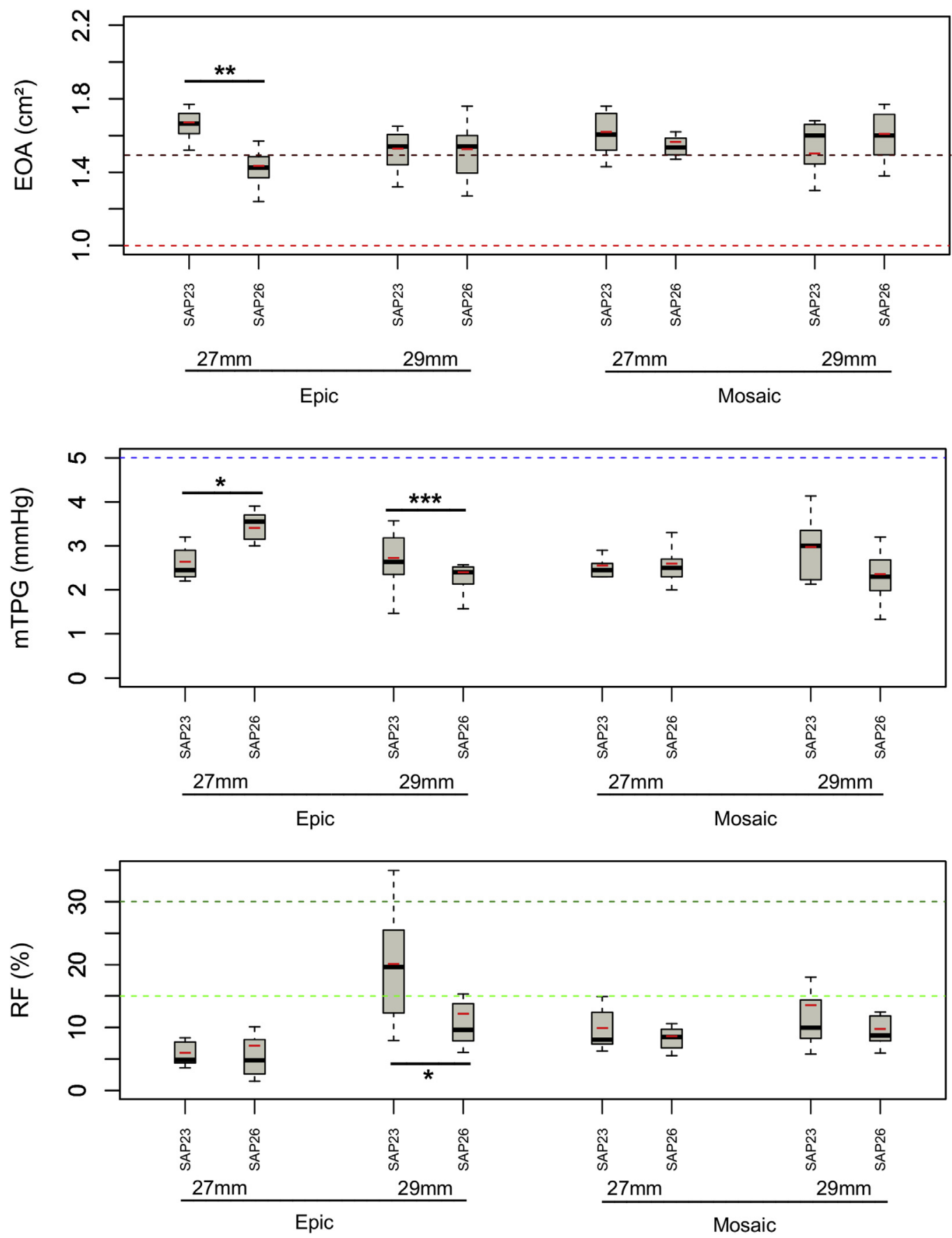

FIGURE 4. Comparison of the hemodynamic performance of valve-in-valve procedures with a Sapien 23 (SAP23) (Edwards Lifesciences, Irvine, Calif) versus a Sapien 26 (SAP26) (Edwards Lifesciences) in 4 surgical bioprostheses. Configurations of SAP23 (left) and SAP26 (right) deployed in each of the following surgical bioprostheses: St Jude Medical (27 and $29 \mathrm{~mm}$; St Paul, Minn) and Mosaic (27 and 29 mm; Medtronic, Minneapolis, Minn). $E O A$, Effective orifice area; $m T P G$, mean transprosthetic pressure gradient; $R F$, regurgitant fraction.

in the present study we found that IOD provided by the manufacturer overestimates by approximately $\sim 13 \%$ $(6 \%-25 \%)$ the actual IOD (Table E1). This is related to the fact that the manufacturer's IOD corresponds to the IOD of the stent, excluding the valve leaflets and the sutures attaching the leaflets to the stent. Hence, the measures of IOD (including the leaflets) as provided in the present study may provide more precise information to select the appropriate Sapien valve size for VinV. In patient candidates for $\mathrm{VinV}$ in whom the information of the 
TABLE 2. Univariate and multivariable analyses of the parameters influencing the hemodynamic performance of the valve-in-valve procedure

\begin{tabular}{|c|c|c|c|c|}
\hline \multirow[b]{2}{*}{ Valve-in-valve condition } & \multicolumn{2}{|c|}{ Univariate } & \multicolumn{2}{|c|}{ Multivariable } \\
\hline & $R^{2}$ & $\begin{array}{c}P \\
\text { value }\end{array}$ & $\begin{array}{l}\text { Estimated } \\
\text { value }\end{array}$ & $\begin{array}{c}P \\
\text { value }\end{array}$ \\
\hline \multicolumn{5}{|l|}{ Effective orifice area $\left(\mathrm{cm}^{2}\right)$} \\
\hline Mitral flow volume (mL) & 0.011 & .250 & & \\
\hline Heart rate (bpm) & 0.000 & .880 & & \\
\hline Mean aortic pressure (mm Hg) & 0.049 & .020 & -0.138 & .0 \\
\hline Bioprosthesis model & 0.016 & .180 & & \\
\hline $\begin{array}{l}\text { Bioprosthesis internal orifice } \\
\text { diameter }(\mathrm{mm})\end{array}$ & 0.110 & $<.001$ & 0.053 & $<.0$ \\
\hline Sapien* oversizing $(\%)$ & 0.027 & .080 & & \\
\hline$R^{2}$ & & & 0.158 & \\
\hline \multicolumn{5}{|l|}{ Transvalvular pressure gradient } \\
\hline Mitral flow volume (mL) & 0.050 & .02 & 0.555 & .0 \\
\hline Heart rate $(\mathrm{b} / \mathrm{min})$ & 0.008 & .33 & & \\
\hline Mean aortic pressure (mm Hg) & 0.007 & .37 & & \\
\hline Bioprosthesis model & 0.012 & .25 & & \\
\hline $\begin{array}{l}\text { Bioprosthesis internal orifice } \\
\text { diameter }(\mathrm{mm})\end{array}$ & 0.203 & $<.001$ & -0.337 & $<.0$ \\
\hline Sapien* oversizing $(\%)$ & 0.079 & .002 & -0.009 & \\
\hline$R^{2}$ & & & 0.259 & \\
\hline \multicolumn{5}{|l|}{ Regurgitant fraction } \\
\hline Mitral flow volume (mL) & 0.002 & .650 & & \\
\hline Heart rate $(\mathrm{b} / \mathrm{min})$ & 0.089 & .001 & 4.533 & $<.00$ \\
\hline Mean aortic pressure (mm Hg) & 0.080 & .002 & 4.110 & $<.00$ \\
\hline Bioprosthesis model & 0.009 & .380 & & \\
\hline $\begin{array}{l}\text { Bioprosthesis internal orifice } \\
\text { diameter }(\mathrm{mm})\end{array}$ & 0.108 & $<.001$ & 0.697 & .12 \\
\hline Sapien* oversizing $(\%)$ & 0.099 & $<.001$ & -0.079 & \\
\hline$R^{2}$ & & & 0.290 & \\
\hline
\end{tabular}

The analysis includes 15 valve-in-valve configurations $\times 8$ hemodynamic conditions. Mitral flow volume, heart rate, mean aortic pressure, and bioprosthesis model are taken as categorical covariates, whereas bioprosthesis internal orifice diameter and percentage of Sapien oversizing are continuous covariates. Effective orifice area, mean transvalvular pressure gradient, and regurgitant fraction are predicted as continuous variables. *Edwards Lifesciences, Irvine, Calif.

actual IOD is not available, computed tomography or 3-dimensional echocardiography may be used to measure the actual IOD and select the appropriate size of transcatheter valve.

Calcification and/or fibrosis of the valve leaflets may hinder optimal deployment of the transcatheter valve and thus alter the hemodynamic performance of the VinV procedure. Also, inadequate positioning of the transcatheter valve (valve too high or too low) may negatively influence the hemodynamic parameters of the procedure. Hence, this study represents the optimal conditions of VinV procedure, and other factors related to the degree of degeneration of the bioprosthetic valves or the positioning of the transcatheter valves may result in worse hemodynamic results compared with those predicted in this in vitro study.

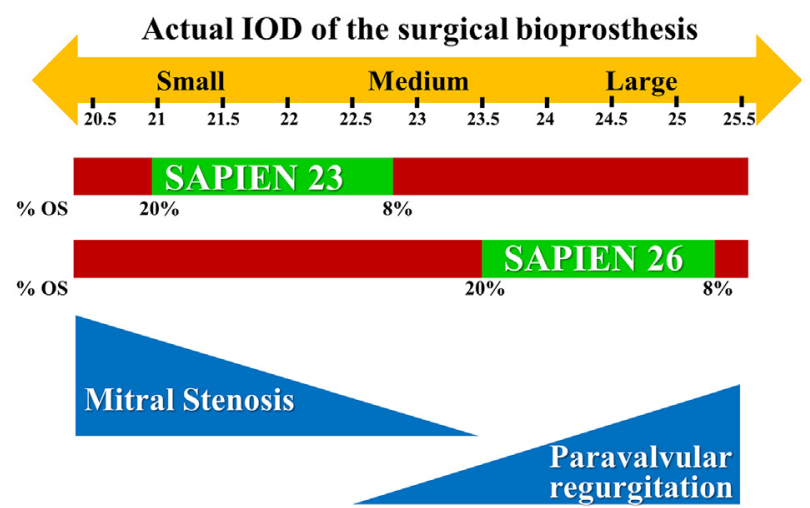

FIGURE 5. Decision aids schema for SAPIEN (Edwards Lifesciences, Irvine, Calif) size choice for optimal valve-in-valve assembly hemodynamic results with IOD and percentage of oversizing thresholds for optimal choice of Sapien size for a failed mitral bioprosthesis. For Sapien 23, Sapien 20 could be considered for internal orifice diameter $<21 \mathrm{~mm}$ and oversized $>20 \%$ (red section on the left of the green bar for Sapien 23). Similarly, Sapien 29 could be considered for internal orifice diameter $>25.3$ and oversized $<8 \%$ (red section on the right of the green bar for Sapien 26).

\section{Limitations}

Although we were not able to document the location of the regurgitation in the context of this in vitro study, it is likely that the regurgitation was paravalvular (ie, between the Sapien valve and the surgical prosthesis).

In this study, we did not measure the leaflet mechanical stress. It is possible that some VinV configurations, and particularly those with larger $\% \mathrm{OS}$ of the transcatheter valve would be associated with higher leaflet mechanical stress. This could, in turn, negatively influence the long-term durability of the VinV.

This study was performed with 2 sizes (23 and 26) of the Sapien valve because Sapien 29 was not available at the time of the study. Due to the limited number of Sapien valves sampled, each Sapien valve was used several times, minimizing the effect of redeployment in reducing the crimping of the stent to the maximum size for insertion in the bioprosthesis.

\section{CONCLUSIONS}

This in vitro study shows that VinV within mitral surgical bioprostheses provides satisfactory hemodynamic results in the majority of cases. However, significant mitral stenosis is more likely to occur when the IOD of the surgical bioprosthesis is $<22 \mathrm{~mm}$ and particularly when the $\%$ OS of the transcatheter valve is $\geq 20 \%$. Significant paravalvular regurgitation may occur when the IOD is $>23 \mathrm{~mm}$ and the $\% \mathrm{OS}$ is $<8 \%$. There may be an advantage of using surgical bioprostheses with flexible stents because this may allow some mild expansion of the bioprosthesis stent and thus some improvement in EOA 
when performing a VinV procedure with balloonexpandable transcatheter valves.

\section{Conflict of Interest Statement}

P.P. has received research support from Edwards Lifesciences Inc (Irvine, Calif) for echocardiography corelab analyses of transcatheter valves. All other authors have nothing to disclose with regard to commercial support.

The authors thank Dr D. Tanné for his continuous support and help in establishing the test protocol, performing experimental works, and providing constructive corrections to this manuscript; and R. Lemaitre and J. Dipieri for their technical help.

\section{References}

1. Makkar RR, Jilaihawi H, Chakravarty T, Fontana GP, Kapadia S, Babaliaros V, et al. Determinants and outcomes of acute transcatheter valve-in-valve therapy or embolization: a study of multiple valve implants in the U.S. PARTNER trial (Placement of AoRTic TraNscathetER Valve Trial Edwards SAPIEN Transcatheter Heart Valve). J Am Coll Cardiol. 2013;62:418-30.

2. Dvir D, Barbanti M, Tan J, Webb JG. Transcatheter aortic valve-in-valve implantation for patients with degenerative surgical bioprosthetic valves. Curr Probl Cardiol. 2014;39:7-27.

3. Cheung A, Webb JG, Wong DR, Ye J, Masson J-B, Carere RG, et al. Transapical transcatheter mitral valve-in-valve implantation in a human. Ann Thorac Surg. 2009;87:e18-20.

4. Cheung AW, Gurvitch R, Ye J, Wood D, Lichtenstein SV, Thompson C, et al. Transcatheter transapical mitral valve-in-valve implantations for a failed bioprosthesis: a case series. J Thorac Cardiovasc Surg. 2011;141:711-5.

5. Seiffert M, Conradi L, Baldus S, Schirmer J, Knap M, Blankenberg S, et al. Transcatheter mitral valve-in-valve implantation in patients with degenerated bioprostheses. JACC Cardiovasc Interv. 2012;5:341-9.

6. Wilbring M, Alexiou K, Tugtekin SM, Sill B, Hammer P, Schmidt T, et al. Transapical transcatheter valve-in-valve implantation for deteriorated mitral valve bioprostheses. Ann Thorac Surg. 2013;95:111-7.

7. Webb JG, Wood DA, Ye J, Gurvitch R, Masson J-B, Rodes-Cabau J, et al. Transcatheter valve-in-valve implantation for failed bioprosthetic heart valves. Circulation. 2010;121:1848-57.
8. Ferrari E, Marcucci C, Sulzer C, von Segesser LK. Which available transapical transcatheter valve fits into degenerated aortic bioprostheses? Interact Cardiovasc Thorac Surg. 2010;11:83-5.

9. Azadani AN, Tseng EE. Transcatheter valve-in-valve implantation for failing bioprosthetic valves. Future Cardiol. 2010;6:811-31.

10. Stühle S, Wendt D, Houl G, Wendt H, Schlamann M, Thielmann M, et al. In-vitro investigation of the hemodynamics of the Edwards Sapien transcatheter heart valve. J Heart Valve Dis. 2011;20:53-63.

11. Walther T, Dehdashtian MM, Khanna R, Young E, Goldbrunner PJ, Lee W Trans-catheter valve-in-valve implantation: in vitro hydrodynamic performance of the SAPIEN+cloth trans-catheter heart valve in the Carpentier-Edwards Perimount valves. J Eur Assoc Cardiothorac Surg. 2011;40:1120-6.

12. Tanné D, Bertrand E, Kadem L, Pibarot P, Rieu R. Assessment of left heart and pulmonary circulation flow dynamics by a new pulsed mock circulatory system. Exp Fluids. 2010;48:837-50.

13. Cheung A, Al-Lawati A. Transcatheter mitral valve-in-valve implantation: current experience and review of literature. Curr Opin Cardiol. 2013;28:181-6.

14. Ferrari E. Transapical aortic "valve-in-valve" procedure for degenerated stented bioprosthesis. Eur J Cardiothorac Surg. 2012;41:485-90.

15. Zoghbi WA, Chambers JB, Dumesnil JG, Foster E, Gottdiener JS, Grayburn PA, et al. Recommendations for evaluation of prosthetic valves with echocardiography and doppler ultrasound: a report from the American Society of Echocardiography's Guidelines and Standards Committee and the Task Force on Prosthetic Valves, developed in conjunction with the American College of Cardiology Cardiovascular Imaging Committee, Cardiac Imaging Committee of the American Heart Association, the European Association of Echocardiography, a registered branch of the European Society of Cardiology, the Japanese Society of Echocardiography and the Canadian Society of Echocardiography, endorsed by the American College of Cardiology Foundation, American Heart Association, European Association of Echocardiography, a registered branch of the European Society of Cardiology, the Japanese Society of Echocardiography, and Canadian Society of Echocardiography. J Am Soc Echocardiogr. 2009;22:975-1014. quiz 1082-4.

16. Baumgartner H, Hung J, Bermejo J, Chambers JB, Evangelista A, Griffin BP et al. Echocardiographic assessment of valve stenosis: EAE/ASE recommendations for clinical practice. J Am Soc Echocardiogr. 2009;22:1-23. quiz.

17. Dvir D, Webb J, Brecker S, Bleiziffer S, Hildick-Smith D, Colombo A, et al Transcatheter aortic valve replacement for degenerative bioprosthetic surgical valves results from the global valve-in-valve registry. Circulation. 2012;126: 2335-44.

Key Words: valve-in-valve, in vitro testing, double activation duplicator, Sapien transcatheter valve 


\section{SUPPLEMENT STATISTICS}

Appendix E1. Description of Intermediary Step of the General Linear Model Presented in Table 2

Assumptions related to the use of a general linear model:

1. Independence of each data point: Because each valve was tested for 8 different conditions, and there is no dependency between those conditions, each data point was considered to be independent.

2. Correct distribution of the residuals.
3. Correct specification of the variance structure.

4. Linear relationship between the response and the linear predictor.

The residual versus fitted graph shows the homogeneity of the variance; no patterns were found in any of those graphs. The normal-QQ graph shows the normality of the distribution, the scale location graph shows no heterogeneity of the variance, and the residual versus leverage would have allowed points having too much influence on the regression coefficients.

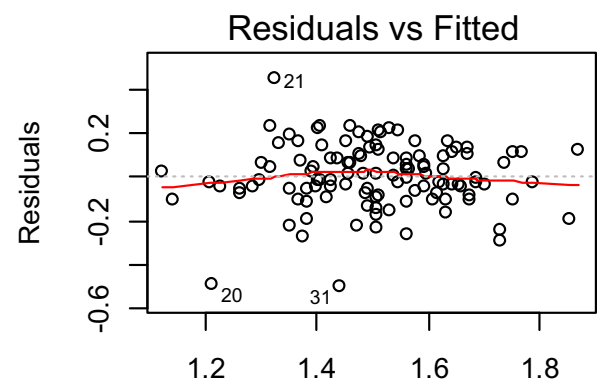

Fitted values

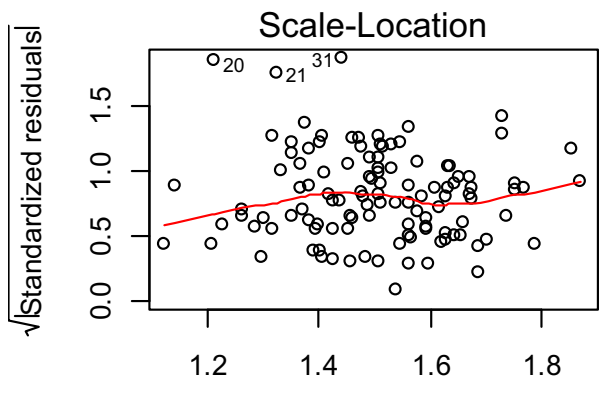

Fitted values
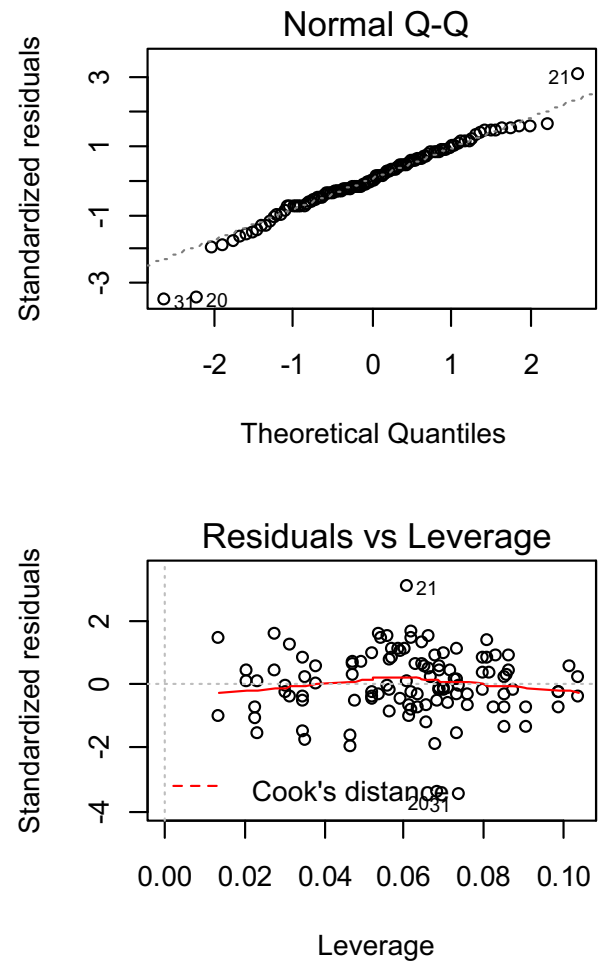

EFFECTIVE ORIFICE AREA. 


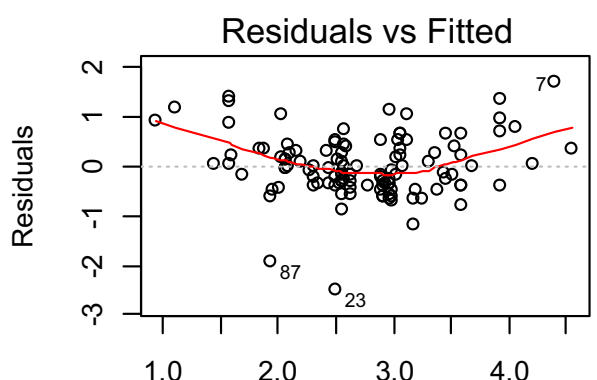

Fitted values

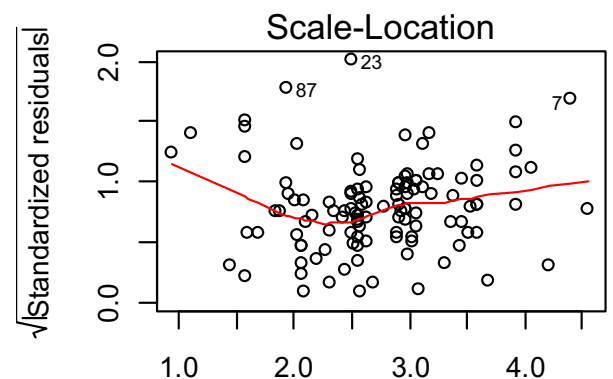

Fitted values

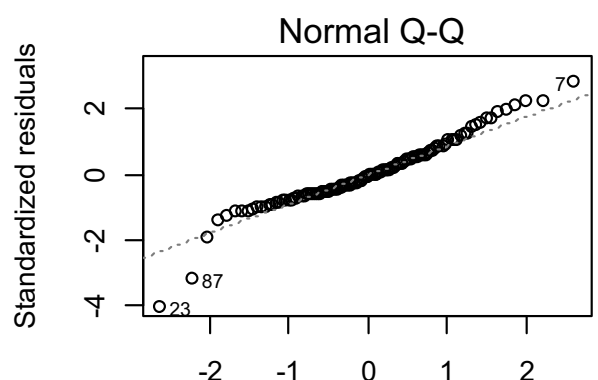

Theoretical Quantiles

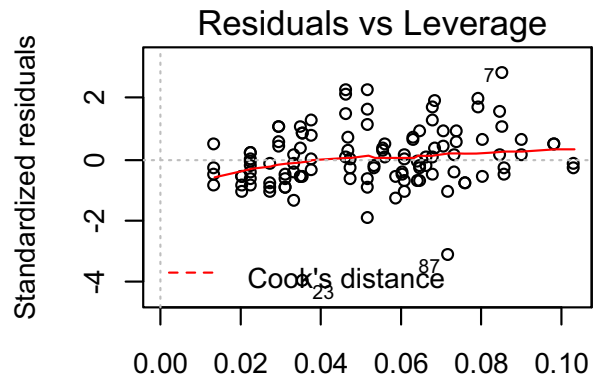

Leverage

MEAN TRANSVALVULAR PRESSURE GRADIENT.

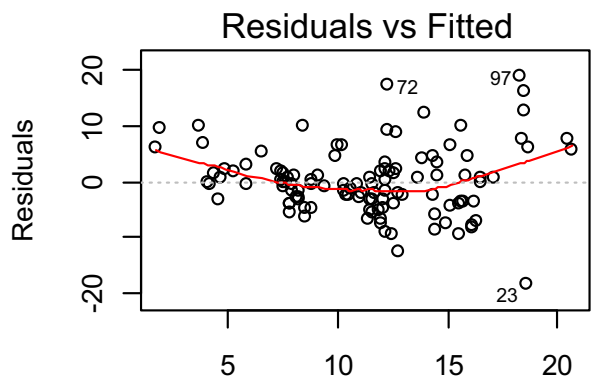

Fitted values

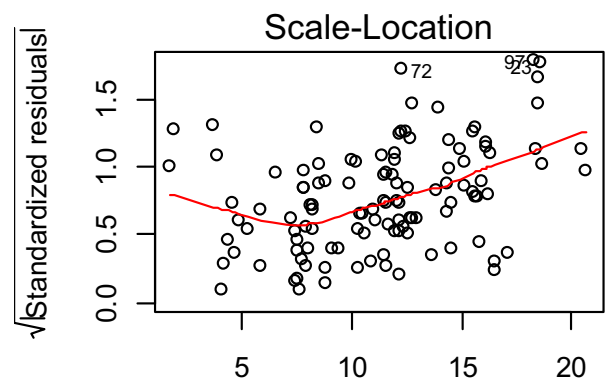

Fitted values

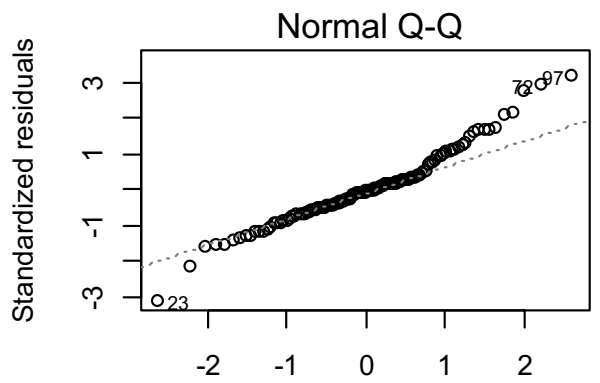

Theoretical Quantiles

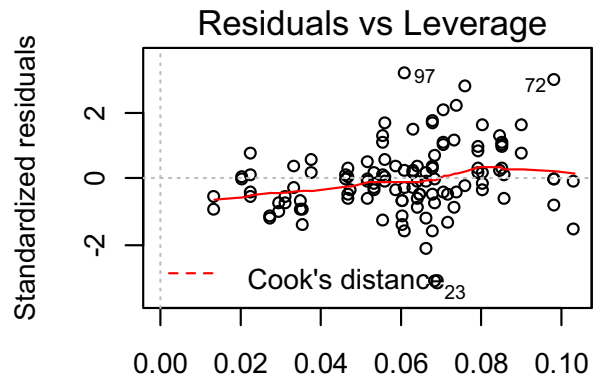

Leverage

\section{REGURGITANT FRACTION.}




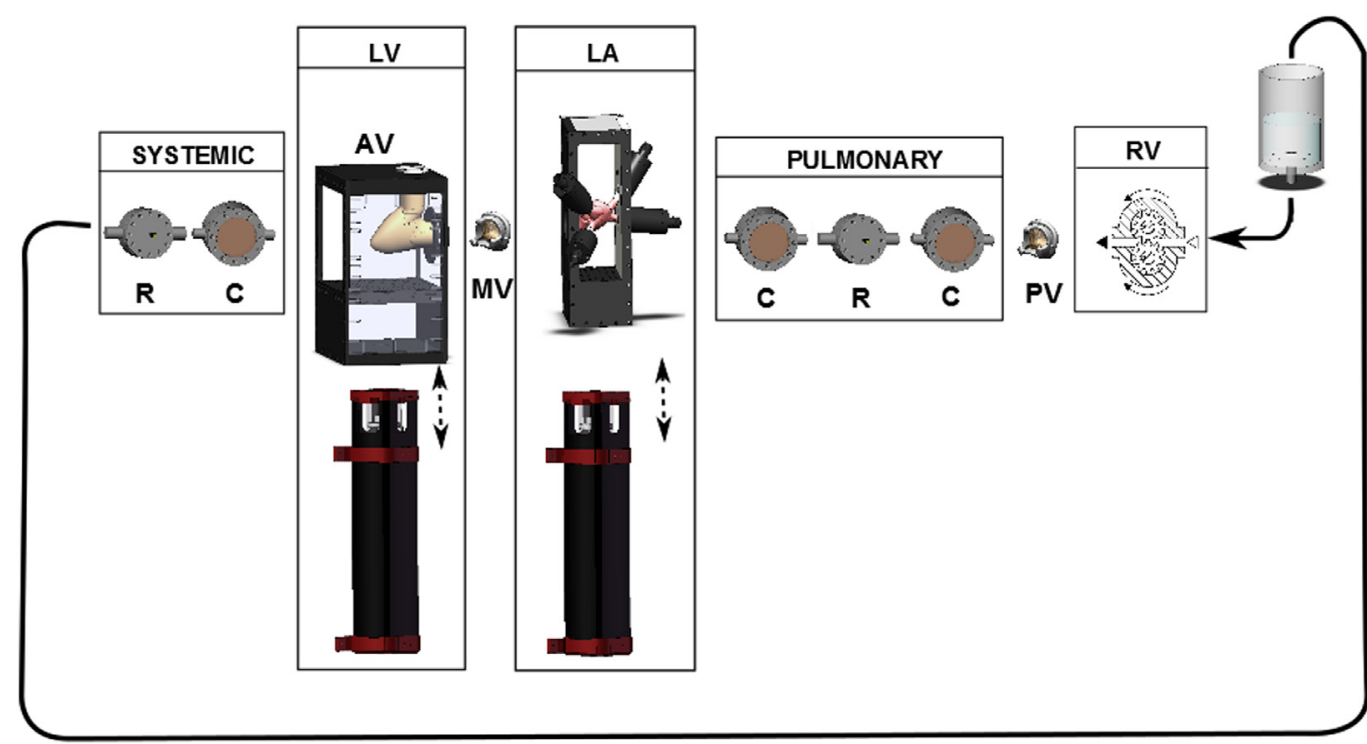

FIGURE E1. Mock simulation system. In vitro system simulating both pulmonary and systemic circulation. Right ventricle $(R V)$ is simulated by a gear pump, the fluid flows through the pulmonary valve $(P V)$ (a Biocor 23 bioprosthesis; St. Jude Medical, St. Paul, Minn) and through compliances $(C)$ and resistance $(R)$ for pulmonary circulation simulation. Both left atrium $(L A)$ and ventricle $(L V)$ are anatomically simulated by silicone moulds immersed in closed cages in which pressure created by 2 Vivitro pumps (Vivitro Lab Inc., Victoria BS, Canada) enable contraction and dilation of the moulds. The aorta is simulated by a passive silicone mould and leads the water-glycerol fluid in the systemic circulation. Resistance in systemic circulation can be manually set to obtain wished mean aortic pressure. Validation of such a system is detailed elsewhere. ${ }^{12} A V$, Aortic valve; $M V$, mitral valve. 

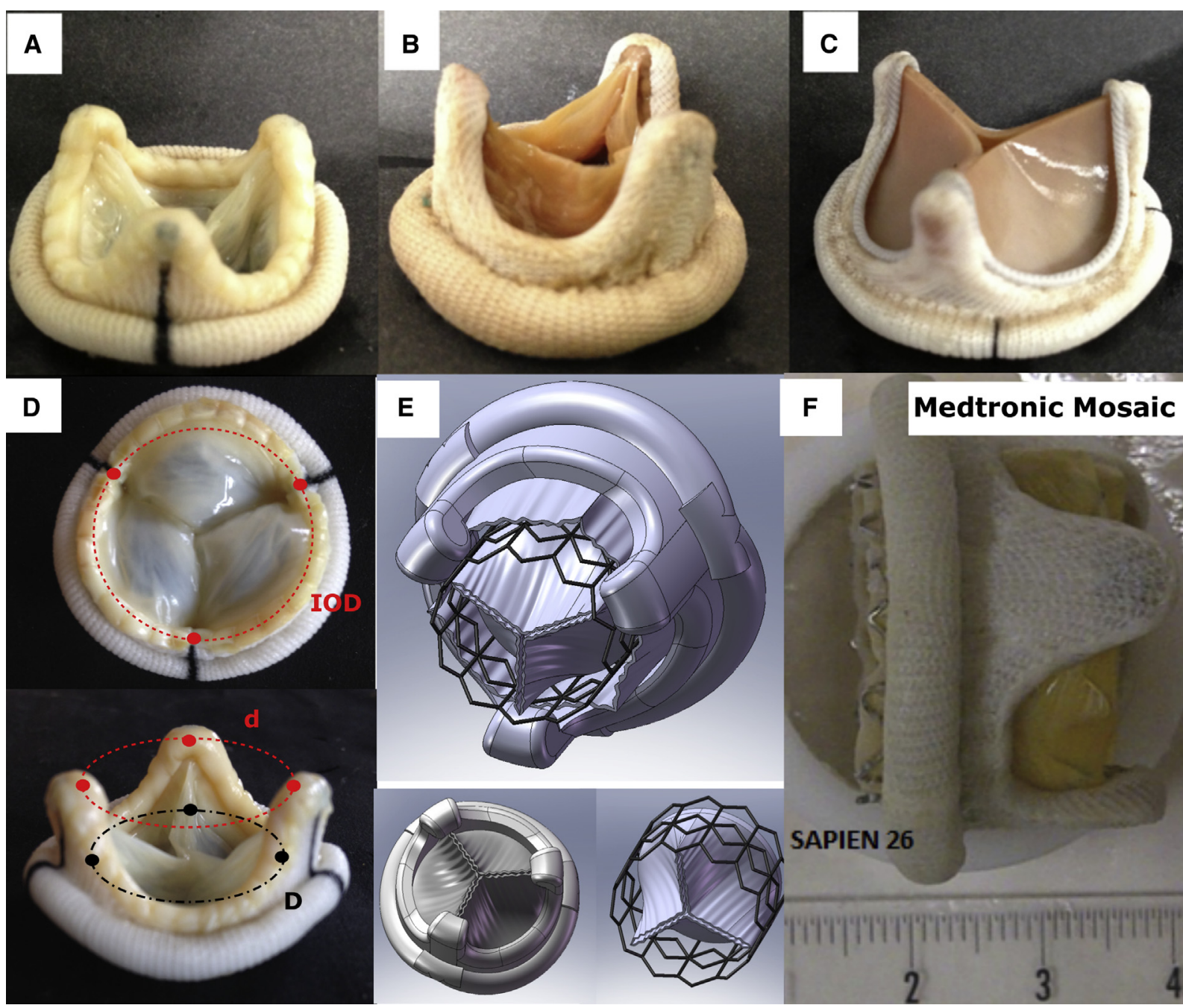

FIGURE E2. Surgical bioprostheses and valve-in-valve assembly. (A) Epic (St Jude Medical, St Paul, Minn), (B) Mosaic Cinch (Medtronic, Minneapolis, Minn), and (C) Magna (Edwards, Irvine, CA). (D) Measurement of bioprosthesis internal orifice diameter by Smartscope optical system (OGP Multi Sensor Measuring Instruments, Singapore) showing outflow diameter and struts diameter. (E) Schema of an Epic 29 mm, a Sapien 23, and a valve-in-valve assembly. (F) Picture of a Sapien 23 deployed in a Medtronic Mosaic $29 \mathrm{~mm}$ bioprosthesis. $I O D$, Internal orifice diameter; $d$, upper diameter; $D$, basis diameter. 
ROC curves for Bioprosthesis IOD
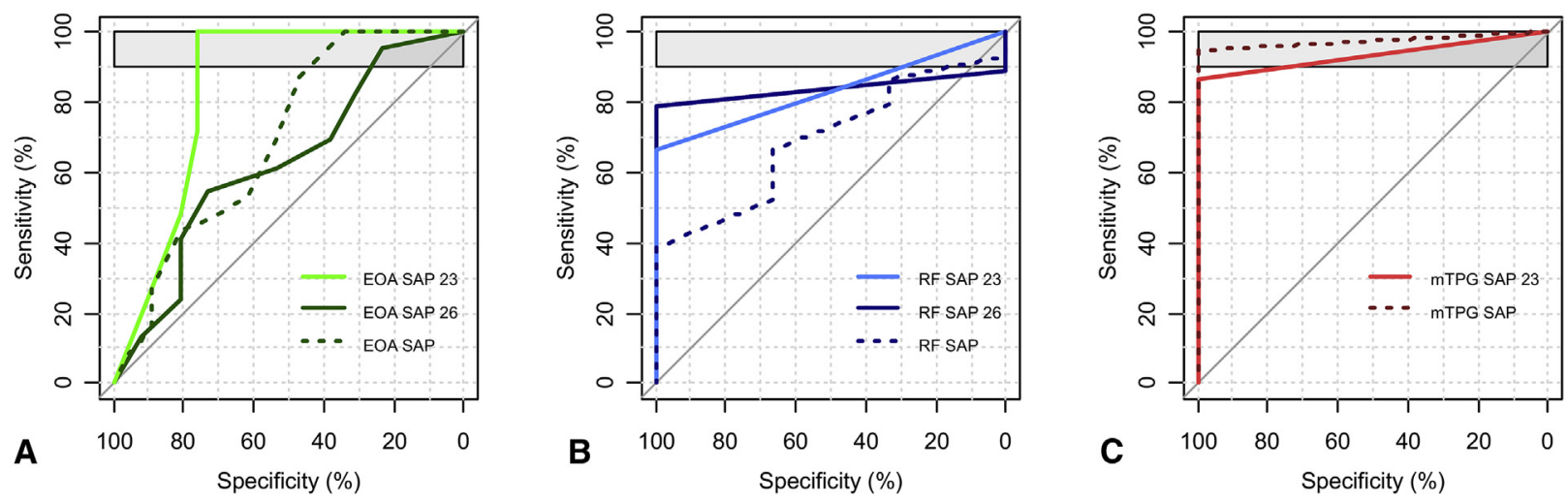

FIGURE E3. Receiver operating characteristic $(R O C)$ curves for moderate prosthesis stenosis (effective orifice area [EOA] and mean transvalvular pressure gradient $[m T P G]$ ) and moderate regurgitation (regurgitant fraction $[R F]$ ). EOA, $\mathrm{mTPG}$, and RF taken as dichotomous values with $(\mathrm{A}) \mathrm{EOA}<1 \mathrm{~cm}^{2}(\mathrm{green})$ and (B) $\mathrm{mTPG}>5 \mathrm{~mm} \mathrm{Hg}$ (red) for prediction of moderate stenosis and (C) RF $>30 \%$ (blue) for prediction of mild regurgitation. Both bioprosthesis internal orifice area and percent of Sapien oversizing covariates were considered as continuous variables. Dark-colored lines are prediction for Sapien 26 (Edwards Lifesciences, Irvine, Calif), pale-colored lines are prediction for Sapien 23 (Edwards Lifesciences). Dashed lines depict are prediction for both Sapien sizes. Of note, no $\mathrm{mTPG}$ was $>5 \mathrm{~mm} \mathrm{Hg}$ in the case of Sapien 26. IOD, Internal orifice diameter.
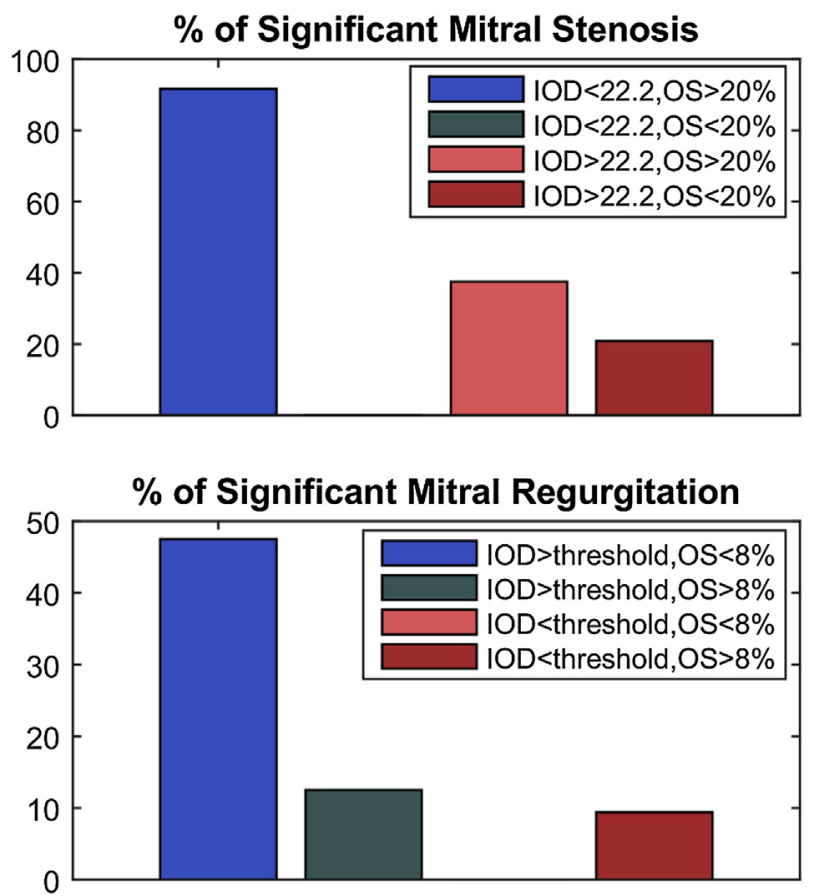

FIGURE E4. Percentage of configuration with significant mitral stenosis and significant mitral regurgitation, according to internal orifice diameter and percentage of oversizing thresholds. (Top) Percentage of the valve-in-valve configuration with significant mitral stenosis defined as effective orifice area $<1.5 \mathrm{~cm}^{2}$ for valve-in-valve in bioprosthesis with an internal orifice diameter $(I O D)>22.2 \mathrm{~cm}$ or IOD $<22.2 \mathrm{~cm}$ and with oversizing $<20 \%$ and $>20 \%$. (Bottom) Percentage of the valve-in-valve configuration with significant mitral regurgitation defined as regurgitant fraction $>15 \%$ for valve-in-valve in bioprosthesis with an IOD $<22.8 \mathrm{~cm}$ for Sapien 23 (Edwards Lifesciences, Irvine, Calif), IOD $<23.5 \mathrm{~cm}$ for Sapien 26 (Edwards Lifesciences), or IOD $>22.8 \mathrm{~cm}$ for Sapien 23, IOD $>23.5 \mathrm{~cm}$ for Sapien 26, and with oversizing $<8 \%$ and oversizing $>8 \%$. OS, Oversizing. 
TABLE E1. Characteristics of the tested surgical bioprostheses and different valve and valve-in-valve configurations tested in this study

\begin{tabular}{|c|c|c|c|c|c|c|c|}
\hline Valve & Size & $\begin{array}{l}\text { Manufacturer } \\
\text { IOD }(\mathbf{m m})\end{array}$ & $\begin{array}{l}\text { Measured } \\
\text { IOD }(\mathbf{m m}) \\
\end{array}$ & $\begin{array}{l}\text { Measured } \\
\text { IOA }\left(\mathrm{cm}^{2}\right)\end{array}$ & $\begin{array}{c}\text { Implanted } \\
\text { Sapien* prosthesis }\end{array}$ & $\begin{array}{c}\text { Nominal orifice area of Sapien* } \\
\text { at full deployment }\end{array}$ & Oversizing (\%) \\
\hline \multirow[t]{4}{*}{ Magna Ease $7300 *$} & 25 & 25 & 23.4 & 4.30 & I & & \\
\hline & 25 & 25 & 23.4 & 4.30 & 26 & 5.31 & 23 \\
\hline & 27 & 27 & 25.2 & 4.99 & I & & \\
\hline & 27 & 27 & 25.2 & 4.99 & 26 & 5.31 & 6 \\
\hline \multirow[t]{12}{*}{ Epic $100 \dagger$} & 25 & 23 & 18.7 & 2.75 & l & & \\
\hline & 25 & 23 & 18.7 & 2.75 & 23 & 4.15 & 51 \\
\hline & 27 & 25 & 21.9 & 3.77 & I & & \\
\hline & 27 & 25 & 21.9 & 3.77 & 23 & 4.15 & 10 \\
\hline & 27 & 25 & 21.9 & 3.77 & 26 & 5.31 & 41 \\
\hline & 29 & 27 & 23.2 & 4.23 & l & & \\
\hline & 29 & 27 & 23.2 & 4.23 & 23 & 4.15 & -2 \\
\hline & 29 & 27 & 23.2 & 4.23 & 26 & 5.31 & 26 \\
\hline & 31 & 29 & 23.2 & 4.23 & I & & \\
\hline & 31 & 29 & 23.2 & 4.23 & 26 & 5.31 & 26 \\
\hline & 33 & 31 & 27.1 & 5.77 & I & & \\
\hline & 33 & 31 & 27.1 & 5.77 & 26 & 5.31 & -8 \\
\hline \multirow[t]{10}{*}{ Mosaic Cinch $\ddagger$} & 25 & 22.5 & 20.2 & 3.20 & l & & \\
\hline & 25 & 22.5 & 20.2 & 3.20 & 23 & 4.15 & 30 \\
\hline & 27 & 24 & 22.5 & 3.98 & I & & \\
\hline & 27 & 24 & 22.5 & 3.98 & 23 & 4.15 & 4 \\
\hline & 27 & 24 & 22.5 & 3.98 & 26 & 5.31 & 34 \\
\hline & 29 & 26 & 23.7 & 4.41 & I & & \\
\hline & 29 & 26 & 23.7 & 4.41 & 23 & 4.15 & -6 \\
\hline & 29 & 26 & 23.7 & 4.41 & 26 & 5.31 & 20 \\
\hline & 31 & 28 & 25.3 & 5.03 & I & & \\
\hline & 31 & 28 & 25.3 & 5.03 & 26 & 5.31 & 6 \\
\hline
\end{tabular}

IOD, Internal orifice diameter; IOA, internal orifice area. *Edwards Lifesciences, Irvine, Calif. †St. Jude Medical, St Paul, Minn. $\ddagger$ Medtronic, Minneapolis, Minn.

TABLE E2. Receiver operating characteristic (ROC) curve analysis for effective orifice area, mean transvalvular pressure gradient, and regurgitant fraction

\begin{tabular}{|c|c|c|c|c|c|c|c|}
\hline & Sensitivity & Specificity & $\begin{array}{c}\text { Negative } \\
\text { predictive value }\end{array}$ & $\begin{array}{c}\text { Positive } \\
\text { predictive value }\end{array}$ & Accuracy & $\begin{array}{l}\text { Area under } \\
\text { the curve }\end{array}$ & Threshold \\
\hline \multicolumn{8}{|c|}{$\mathrm{ROC}$ analysis for effective orifice area $<1.5 \mathrm{~cm}^{2}$} \\
\hline Bioprosthesis IOD for all Sapien* & 47 & 88 & 71 & 73 & 0.713 & 69.9 & $<22.2$ \\
\hline Bioprosthesis IOD for Sapien $23^{*}$ & 76 & 100 & 82 & 100 & 0.886 & 84.2 & $<21.0$ \\
\hline Bioprosthesis IOD for Sapien $26^{*}$ & 73 & 53 & 77 & 48 & 0.606 & 62.3 & $<23.5$ \\
\hline \multicolumn{8}{|c|}{ ROC analysis for mean transvalvular pressure gradient $<5 \mathrm{~mm} \mathrm{Hg}$} \\
\hline Bioprosthesis IOD for all Sapien* & 100 & 95 & 100 & 25 & 0.948 & 97.4 & $<19.5$ \\
\hline Bioprosthesis IOD for Sapien $23^{*}$ & 100 & 86 & 100 & 25 & 0.864 & 93.2 & $<19.5$ \\
\hline \multicolumn{8}{|c|}{ ROC analysis for regurgitant fraction $<30 \%$} \\
\hline Bioprosthesis IOD for all Sapien* & 100 & 39 & 100 & 4 & 0.791 & 69.8 & $>22.8$ \\
\hline Bioprosthesis IOD for Sapien $23^{*}$ & 100 & 67 & 100 & 12 & 0.408 & 83.3 & $>22.8$ \\
\hline Bioprosthesis IOD for Sapien $26^{*}$ & 100 & 79 & 100 & 6 & 0.788 & 83.6 & $>25.3$ \\
\hline
\end{tabular}

